\title{
Evaluation of the Exercise in Adult Nursing Education
}

Kumiko Kudo", Takayuki Kumasaka, Hiroko Fujisawa, Masahiro Shigeishi

Japan University of Health Sciences, Faculty of Health Sciences, Department of Nursing 1961-2 Satte, Satte-city, Saitama 340-0113, Japan

DOI: $\underline{10.36348 / \text { sjnhc.2020.v03i09.002 }}$

| Received: 12.09 .2020 | Accepted: 22.09.2020 | Published: 30.09 .2020

*Corresponding author: Kumiko Kudo

Abstract

Due to the sophistication and complexity of medical care, nurses are required to have a high level of nursing practice skills. A survey of private university and junior college teachers revealed that the most prevalent problems with students were lack of independence, basic academic ability, and motivation to learn. Class exercises help bring out students' independence and also play a key role in laying the foundation for good clinical judgment. Therefore, it is necessary to consider exercises that enable students to learn more effectively. This study aimed to assess the effectiveness of exercises in adult nursing classes using student class evaluations from 2018 and 2019. We had students perform exercises in class and then had them fill out a survey afterward. The average score of each question item was 4 or more in both 2018 and 2019, and all exercises were highly evaluated. Even if the students who took the course changed, the exercise earned a positive evaluation. For self-monitoring blood glucose and total parenteral nutrition, items were significantly different between 2018 and 2019, and higher evaluations were obtained in 2019. It is necessary to repeat the evaluation of the exercises, but the exercise items selected this time for study were found meaningful for students, and the time allocation was appropriate. The task is to establish a prelearning and demonstration method that enables students to independently learn and to secure teachers and improve teaching their teaching ability.

Keywords: Nursing student, Nursing Education, Evaluation study, Adult Nursing.

Copyright @ 2020: This is an open-access article distributed under the terms of the Creative Commons Attribution license which permits unrestricted use, distribution, and reproduction in any medium for non-commercial use (NonCommercial, or CC-BY-NC) provided the original author and source are credited.

\section{INTRODUCTION}

Due to the sophistication and complexity of medical care, nurses are required to have a high level of nursing practice skills. The IOM report states that nursing is the key to the safety of medical care and its resolution, and that it is important to obtain higher levels of education and training [1]. In order to provide high-quality education, even in Japan, studies are being carried out on how nursing human resources should be trained at universities and the content and methods of basic nursing education [2, 3].

A survey of private university and junior college teachers of Japan conducted in 2016 revealed problems with students, such as lack of independence, basic academic ability, and motivation to learn [4]. A study conducted in Tehran also found that the most important barriers to clinical education in the clinical setting were lack of student interest and motivation [5]. The IOM Report also recommends that nurses carry out lifelong learning [1], and it is important to promote the independence and learning motivation of nursing students in basic nursing education.
Exercises help students have a direct or indirect simulated experience within a classroom. They are ways to revise students' actions by reviewing their thoughts and actions and confirming or proving wrong one's perception. So that reason they can bring out students' independence [6]. Exercises also have the advantage of increasing interest in tasks and learning, as students can experience using their own body and get reactions from others on the spot [7]. Exercises play a key role in laying the foundation for good clinical judgment.

The Adult Nursing Methodology exercise (Chronic Aid Theory) at University A is aimed for the students to understand the skills necessary to give nursing care to adult patients and patients with chronic diseases, and to consider the points to be noted and a better way. A "chronic" condition is one that cannot be cured by medical intervention. Regular monitoring and supportive care are required to reduce the extent of the illness and maximize patient function and responsibility for self-care [8]. Chronic diseases progress slowly over a long period of time and include heart disease, stroke, cancer, chronic respiratory disease, and diabetes. WHO identifies these as noncommunicable diseases (NCDs), 
is the leading cause of death worldwide and one of the major health problems of the 21 st century [9]. There are various long-term treatments for chronic diseases, such as pharmacotherapy, diet therapy, exercise therapy, home oxygen therapy, and artificial dialysis. These treatments are not intended to cure but to enable patients to lead their own daily lives, to prevent their illness from worsening, and to prevent complications [10]. It is important for nurses to support people with chronic illness so that patients can accept their disease and learn to live with it, and to provide continuous support to promote self-management [11]. Therefore, skills nurses must acquire vary widely.

In Japan, the curriculum of nursing education at universities does not have time to practice all clinically required nursing skills. Therefore, it is necessary to consider a method that lets students learn more effectively in a limited amount of time. This study aimed to assess effectiveness of the practice method in adult nursing education using student class evaluations from 2018 and 2019.

\section{METHODS}

\section{Exercise overview}

The contents of the exercise were selfmonitoring blood glucose (SMBG), total parenteral nutrition (TPN), activities of daily living (ADL), and alternative therapy mainly used in chronic phasemakeup therapy (MAKE). The students were divided into two classes, and the same exercise was performed in each class. Students were randomly assigned to groups. Each class consisted of 11 groups, with 5 to 6 students in each group. In SMBG, TPN, and ADL, 5 teachers were in charge of exercises, and 1 teacher was in charge of 2 or 3 groups. In MAKE, 1 beauty expert from outside the university and 1 teacher from University A were in charge of the exercise. Students were given a manual of the nursing skills for the exercises in advance. In addition, they were presented with a prelearning task about the purpose, adaptation, procedure, and points of attention for the nursing skills, to be submitted on the day of the exercise.

Exercises lasted for 90 minutes. In SMBG, TPN, and ADL, after confirming the attendees and the prelearning task (5 minutes), a demonstration was conducted by the teacher (15 minutes). Next, the students were divided into groups in order to experience both the role of the nurse and the role of the patient (45 minutes). After this experience, the group members shared what they had noticed and learned, points to keep in mind, and so forth (15 minutes), and finally, they presented what they had learned (10 minutes).

The SMBG exercise sets a scene in which the patient performs SMBG for the first time. The student in the role of the nurse explains procedures and points to keep in mind. The student in the role of the patient punctured his or her own fingertip with a puncture needle and measured the blood glucose level using a simple blood glucose meter. The exercises included hemostasis, checking the blood sugar level, and cleaning up items that had been used such as used needles and alcohol swabs.

In the TPN exercise, the dressing was changed assuming that a central venous catheter was inserted into the subclavian vein of the patient. The dressing must be peeled off and a new dressing applied and after disinfection. In this exercise, the genders are separated because students in the role of patients expose the precordium. In addition, in this exercise, there was not enough time, and in order to shorten the preparation time, the number of students who experienced the role of patient was 2 in the group, and the patient experience was shared within the group.

The ADL exercise included manual muscle testing of the upper and lower limbs, measurement of the range of motion of the shoulder joint, and training to prevent or improve range of motion limitations.

The MAKE exercises were allocated a different amount of time from the other three exercises. First, a lecture (50 minutes) was given on the purpose, function, and role of makeup, the effects brought about by makeup, examples of makeup use at medical and nursing care sites, and angel makeup. After the beauty expert gave a demonstration (10 minutes), students both applied makeup to others and had it applied to them (30 minutes).

\section{RESEARCH METHODS Subjects}

The subjects were second-year students at University A who took Adult Nursing Methodology II (Chronic Aid Theory) in 2018 and 2019.

\section{Survey method}

An anonymous questionnaire survey was conducted using a questionnaire that was created by extracting question items linked to the contents of this exercise from the Nursing University Class Process Evaluation Scale <-for Nursing Skills Exercise-> developed by Funashima et al. [12,13]. The questionnaire was distributed to all students who took the exercise, and those who agreed to the survey put it in a box installed in the exercise room.

The questionnaire consisted of 13 items. Questions 1-12 were rated on a 5-point scale: very applicable, approximately applicable, somewhat applicable, not applicable, and not applicable at all. Question 13 asked freely for opinions, impressions, and requests for the exercise.

\section{The 12 items are as follows}

1. The course hours were suitable for the practice content. 
2. The practice was not very difficult and easy to understand.

3. The purpose and gist of the practice were easy to understand.

4. I appropriately understand the significance of the practice.

5. The time and speed of the demonstrations were appropriate.

6. The practice proceeded appropriately, and I could practice sufficiently.

7. The advance assignments had suitable content and quantity for helping understand the practice.

8. Teaching materials to aid understanding of the course content such as printouts and videos were used appropriately.

9. I could interact with the students sufficiently during the practice.

10. By experiencing the role of the patient, I could think about devised and regard when to provide nursing skills.

11. I could consult the teacher whenever needed.

12. Teachers were supportive toward students' thinking and self-action.

\section{Analysis method}

Average scores and standard deviations were calculated by giving 1 point for "not applicable at all" to 5 points for "very applicable." In addition, the Cronbach $\alpha$ reliability coefficient ( $\alpha$ coefficient) was calculated to examine the reliability of the questionnaire. The Mann-Whitney $U$ test was performed, and a comparison between 2018 and 2019 was performed. IBM SPSS Statistics 24 was used for statistical processing. For question 13, similar answers were grouped together.

\section{Ethical concerns}

We explained to the subjects, both in writing and verbally, the purpose of the research and the content of the survey. We also explained that their name would not be used, that they would not be paid for their cooperation, and that whether they cooperated or not would not affect their grades. In addition, we explained that the obtained information would not be used for anything other than this research, it would kept in a locked place in the laboratory of the university, and deleted and destroyed when the results were completed. This research was conducted with the approval (2827-1) of the Research Ethics Committee of the Japan University of Health Sciences.

\section{RESULTS}

The number of students who agreed to participate in the study is as follows. In 2018, SMBG: 103, TPN: 101, ADL: 101, MAKE: 105. In 2019, SMBG: 106, TPN: 100, ADL: 100, MAKE: 96. The $\alpha$ coefficient was in the range of 0.95 to 0.99 in 2018 and 0.91 to 0.98 in 2019 , and the questionnaire secured reliability by internal consistency.

\section{Evaluation of the SMBG exercise}

The average score of each question item was 4.64 or more in 2018 and 4.80 or more in 2019 , and all questions were higher in 2019 (Table 1). Significant differences were observed in Q.3, 6, 9, $10(\mathrm{p}<.05)$ and Q.11 ( $\mathrm{p}<.01)$.

Table-1: Evaluation of SMBG exercise

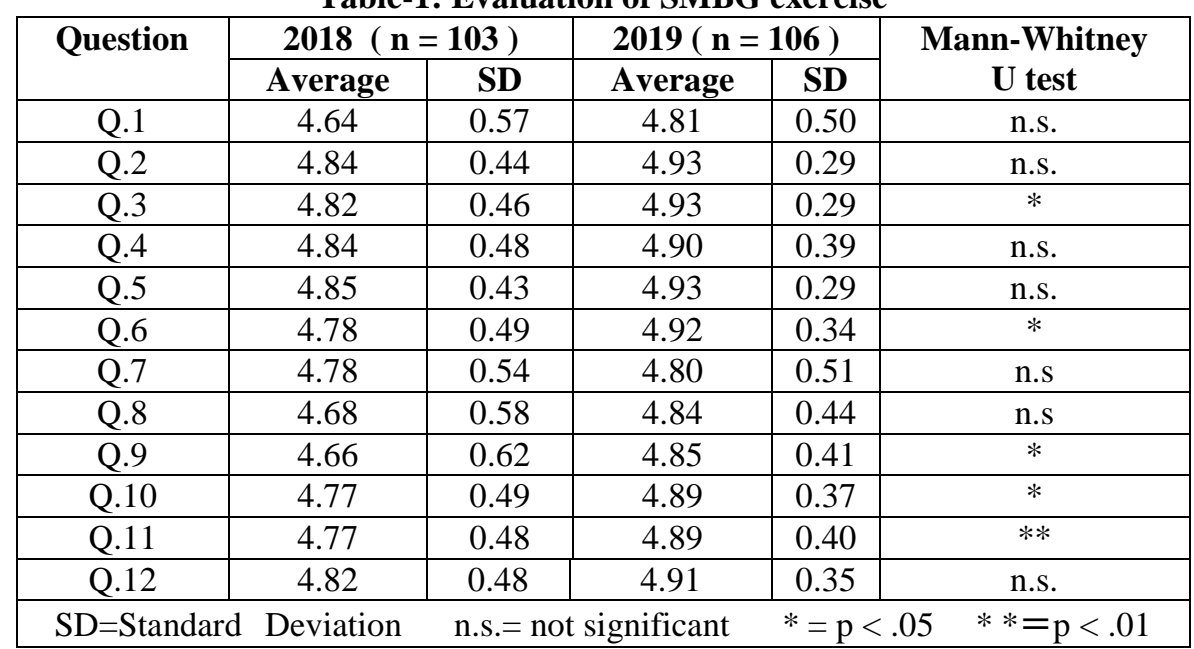

\section{Evaluation of TPN exercise}

The average score of each question item was 4.55 or more in 2018 and 4.83 or more in 2019 , and all items were higher in 2019 (Table 2). Significant differences were seen in Q.3, 4, 10, 11, 12 (p <.05) and Q.1, 2, 6, 9 ( $\mathrm{p}<.01)$. In Q.1, the difference between the average scores of 2018 and 2019 was 0.3 , the largest difference among the four exercises. 
Table-2: Evaluation of TPN exercise

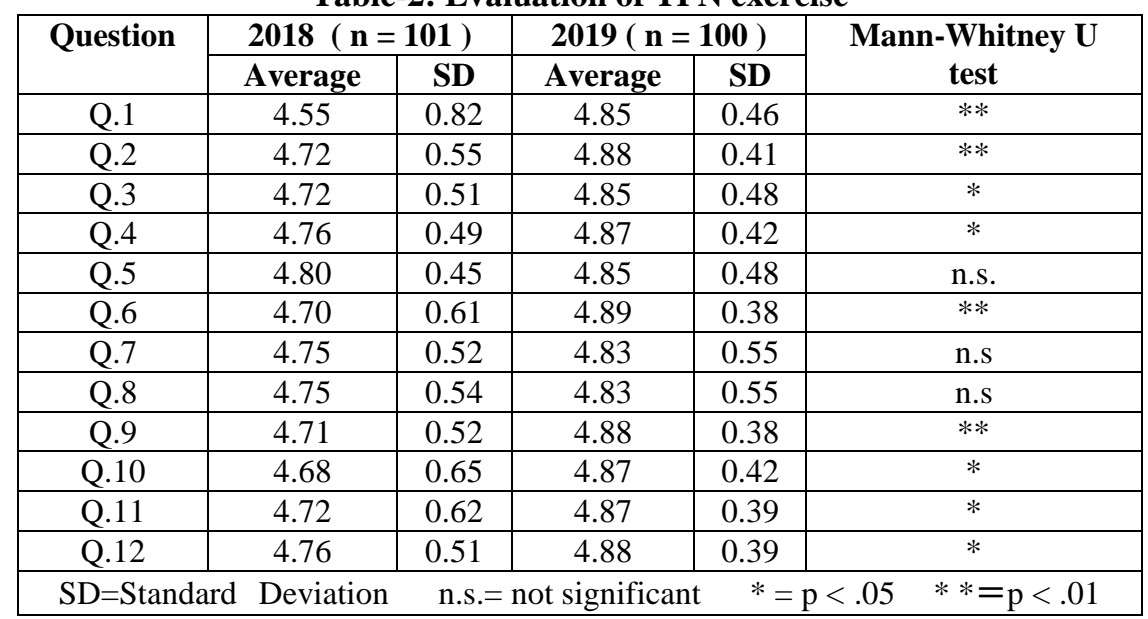

\section{Evaluation of $A D L$ exercise}

The average score of each question item was 4.73 or more in 2018 and 4.78 or more in 2019 (Table
3). Except for Q.9 and Q.11, 2019 was higher than 2018, but there were no significant differences.

Table-3: Evaluation of ADL exercise

\begin{tabular}{|c|c|c|c|c|c|}
\hline \multirow{2}{*}{ Question } & \multicolumn{2}{|c|}{$\mathbf{2 0 1 8}(\mathbf{n}=\mathbf{1 0 1})$} & \multicolumn{2}{c|}{$\mathbf{2 0 1 9}(\mathbf{n = 1 0 0})$} & \multirow{2}{*}{$\begin{array}{c}\text { Mann-Whitney } \\
\text { U test }\end{array}$} \\
\cline { 2 - 5 } & Average & SD & Average & SD & n.s. \\
\hline Q.1 & 4.75 & 0.57 & 4.84 & 0.47 & n.s. \\
\hline Q.2 & 4.78 & 0.50 & 4.86 & 0.45 & n.s. \\
\hline Q.3 & 4.78 & 0.54 & 4.86 & 0.37 & n.s. \\
\hline Q.4 & 4.80 & 0.49 & 4.86 & 0.43 & n.s. \\
\hline Q.5 & 4.81 & 0.48 & 4.88 & 0.41 & n.s. \\
\hline Q.6 & 4.80 & 0.49 & 4.84 & 0.44 & n.s. \\
\hline Q.7 & 4.75 & 0.54 & 4.86 & 0.40 & n.s. \\
\hline Q.8 & 4.73 & 0.58 & 4.85 & 0.44 & n.s. \\
\hline Q.9 & 4.79 & 0.52 & 4.78 & 0.54 & n.s. \\
\hline Q.10 & 4.80 & 0.51 & 4.87 & 0.39 & n.s. \\
\hline Q.11 & 4.81 & 0.48 & 4.81 & 0.47 & n.s. \\
\hline Q.12 & 4.78 & 0.52 & 4.83 & 0.45 & n.s.= not significant \\
\hline \multicolumn{7}{|l|}{ SD=Standard Deviation } \\
\hline
\end{tabular}

\section{Evaluation of MAKE exercise}

The average score of each question item was 4.78 in 2018 and 4.83 in 2019 (Table 4). Q.10, 11, and
12 were lower in 2019 than 2018, but there was no significant difference.

Table-4: Evaluation of MAKE exercise

\begin{tabular}{|c|c|c|c|c|c|}
\hline \multirow[t]{2}{*}{ Question } & \multicolumn{2}{|c|}{$2018(n=105)$} & \multicolumn{2}{|c|}{$2019(n=96)$} & \multirow{2}{*}{$\begin{array}{c}\text { Mann-Whitney } \\
\text { U test }\end{array}$} \\
\hline & Average & SD & Average & SD & \\
\hline Q.1 & 4.84 & 0.46 & 4.86 & 0.46 & n.s. \\
\hline Q.2 & 4.86 & 0.43 & 4.87 & 0.43 & n.s. \\
\hline Q.3 & 4.88 & 0.38 & 4.90 & 0.38 & n.s. \\
\hline Q.4 & 4.85 & 0.46 & 4.90 & 0.46 & n.s. \\
\hline Q.5 & 4.87 & 0.39 & 4.87 & 0.39 & n.s. \\
\hline Q.6 & 4.78 & 0.54 & 4.86 & 0.54 & n.s. \\
\hline Q.7 & 4.86 & 0.43 & 4.87 & 0.43 & n.s. \\
\hline Q.8 & 4.85 & 0.46 & 4.86 & 0.46 & n.s. \\
\hline Q.9 & 4.83 & 0.49 & 4.83 & 0.49 & n.s. \\
\hline Q.10 & 4.85 & 0.43 & 4.83 & 0.43 & n.s. \\
\hline Q.11 & 4.88 & 0.38 & 4.84 & 0.38 & n.s. \\
\hline Q.12 & 4.89 & 0.38 & 4.86 & 0.38 & n.s. \\
\hline
\end{tabular}




\section{Free responses}

There were many positive opinions such as "It was easy to understand" and "It was fun," but there were also negative opinions such as "It was difficult to see the demonstration" (Table 5).

Table-5: Free responses

\begin{tabular}{|c|l|l|}
\hline \multirow{2}{*}{ SMBG } & \multicolumn{1}{|c|}{$\mathbf{2 0 1 8}$} & \multicolumn{1}{|c|}{2019} \\
\hline TPN & & $\begin{array}{l}\text { It was very easy to understand. } \\
\text { It was easy to ask the teacher a question. (2) } \\
\text { I was able to learn enough content in time. } \\
\text { I was very scared when puncturing. } \\
\text { It was difficult to see the demonstration. }\end{array}$ \\
\hline ADL & $\begin{array}{l}\text { It was fun. } \\
\text { MAKE }\end{array}$ & $\begin{array}{l}\text { I was able to practice smoothly with the demonstration. } \\
\text { It was very easy to understand. (2) }\end{array}$ \\
\hline $\begin{array}{l}\text { It was fund } \\
\text { The conversation became lively. }\end{array}$ & $\begin{array}{l}\text { It was easy to understand. } \\
\text { It was difficult to see the demonstration. (2) }\end{array}$ \\
\hline $\begin{array}{l}\text { It was embarrassing to receive makeup from others. } \\
\text { It was fun. (5) }\end{array}$ & \\
\hline
\end{tabular}

\section{DISCUSSION}

The average score of each question item was 4 or more in both 2018 and 2019, and the exercise was highly evaluated. The exercises obtained positive evaluations even if the students who took the course changed. For SMBG and TPN, there were items with significant differences from 2018, and higher evaluations were obtained in 2019.

The exercises were chosen based on nursing techniques that would be required in an adult chronic nursing practice for nursing students in the third year. In recent years, people's interest in complementary and alternative medicine/therapy (CAM/CAT) has increased [14]. According to research by Nitta et al. [15], many nurses are interested in techniques for relieving physical and psychological distress, but the problem is that their skills are immature. These nurses have said that they want opportunities for studying CAM as basic nursing education or as continuing education after graduation. In recent years, CAM/CAT has increased in nursing education [16,17], and University $A$ has adopted MAKE. The average score of Q.3 and Q.4 for all exercises was 4.7 or higher, indicating that the student was able to understand the significance and purpose of the exercise. The free responses of SMBG and MAKE show that the students could understand the patient's feelings by experiencing the fear of a needle puncturing and the embarrassment of receiving makeup. The exercise was meaningful because the experience led to issues and interests such as "how to consider patient's fear and embarrassment." Because it is difficult to incorporate all the nursing skills required in clinical practice into exercises, it is necessary to continue examining the contents of the exercises in order to make them more meaningful.

Regarding time allocation, previous studies have shown that exercises that spend a lot of time on technical experiences have a higher student rating than exercises that spend a lot of time on demonstrations and explanations [18]. From the results of Q.1, 6, 9, and 10, it seems that students were searching for better methods for treating patients while discussing these issues with each other, and they practiced slowly and carefully, and the time allocation was appropriate. The TPN, which was said to have no time to spare, was rated higher in 2019 , indicating that the teachers were able to consider and adjust while watching the progress of the students. Arai et al. [19] pointed out four steps to foster student independence: assignment of tasks, search for solutions, responsible behavior, and realization of growth. If students do not have enough time for discussion and practice, they will not be able to take the steps of "search for solutions" and "realization of growth," so time management is important.

Q11 and free responses indicated that it was easy to ask the teacher questions. However, there were times when 1 teacher was in charge of 15 students in 3 groups, and it remains questionable whether they were sufficiently involved with the students. In addition, because MAKE has difficulty securing teachers due to schedules, only external teachers and 1 University A teacher were in charge of the exercises. Jasemi et al. reported that improving the quality of clinical education through recruiting capable trainers with good communicational skills could motivate student [20]. Teachers must confirm that the procedures are based on 
evidence, and they must ask questions to promote students' understanding and develop thinking. Capable teachers must be hired, and they must have adequate educational skills.

Students were given a procedure book in advance and were assigned prelearning tasks, but the content of learning varied greatly between individuals. Insufficient prelearning means that students will only learn the procedure and will not be able to acquire evidence-based skills. In today's Japan where reduced motivation of learning and disparities in basic academic achievement are considered issues, how to motivate learning is a major issue.

The distributed procedure manual alone does not give images of the demonstration, but teachers conduct demonstrations before the students try the exercises. However, these can be hard to see for a large number of students. There was an opinion, given in the free description that the demonstration was difficult to see. The demonstration method also needs to be modified.

\section{CONCLUSIONS}

All the exercises were highly evaluated by students in both 2018 and 2019. It is necessary to repeat the evaluation of the exercise items, but it was found that the exercise items selected in this study were meaningful for students, and the time allocation was appropriate.

The task is to establish a prelearning and demonstration method that enables students to independently work on learning and to secure teachers and guarantee their teaching ability and communication skills. In addition, it is necessary to continue evaluation so that exercises that enable effective learning in a limited time can be performed in a social situation where high nursing practice skills are required by nurses.

\section{Conflicts of Interest}

The authors declare no conflicts of interest associated with this manuscript.

\section{Funding Statement}

The research did not receive specific funding but was performed as part of the employment at the Japan University of Health Sciences.

\section{ACKNOWLEDGMENTS}

The authors would like to thank the students who cooperated in this research. We also thank Enago (www.enego.jp) for the English language review.

\section{REFERENCES}

1. Institute of Medicine. (2010). Future of Nursing: Leading Change, Advancing Health. The National Academy of Science, Washington, DC, USA.
2. Ministry of Education, Culture, Sports, Science, and Technology. (2019). Study Group on Nursing Human Resources Training at Universities, [Cited December 23, 2019]. Available from: https://www.mext.go.jp/b_menu/shingi/chousa/kou tou/098/index.html.

3. Ministry of Health, Labor and Welfare. (2019). Nursing Basic Education Study Group, [Cited December 23, 2019]. Available from: https://www.mhlw.go.jp/stf/shingi/otherisei_544319.html.

4. Public Interest Incorporated Association of Private University Information Education. (2017). White Paper on Class Improvement for Private University Teachers -Survey Results for FY2016. Available from:

http://www.juce.jp/LINK/report/hakusho2016/haku sho2016.pdf.

5. Rahimi, A., \& Ahmadi, F. (2005). The obstacles and improving strategies of clinical education from the viewpoints of clinical instructors in tehran's nursing Schools. Iranian Journal of Medical Education, 5(2): 73-80.

6. Nishiwaki, Y., Okamura, N., \& Kobayashi, M. (2001). Evaluations of the Basic Nursing Skill Practice Process Using "Evaluation Scale of Nursing University [for Practice of Nursing Skill]". Bulletin of Niigata Prefectural Junior College of Nursing, 7, 65-75.

7. Funashima, N. (2013). Class development \& nursing education -toward high quality lectures, exercises, \& practices. Tokyo: Igaku-Shoin.

8. Cluff, L.E. (1981). Chronic disease, function and the quality of care. Journal of Chronic Diseases, 34(7), 299-304.

9. World Health Organization. (2018) Noncommunicable diseases country profiles.

10. Kuroe, Y. (Ed). (2018). Adult nursing1 introduction to adult nursing/adult health. 6th ed. Tokyo: medical friend.

11. Suzuki, K., Nozawa, A., Mori, K. (Eds). (2015). Adult Nursing; Chronic Nursing. Revised 2nd ed.Supporting People Living with Diseases-. Tokyo: Nankodo.

12. Funashima, N. (Ed). (2011). Measurement tools file for nursing practice/training -from the development process to the actual application. 109117, Tokyo: Igaku-Shoin.

13. Funashima, N., \& Sugimori, M. (2007). Nursing education evaluation theory -realization of highquality self-inspection and evaluation. 37-45, Tokyo: Bunkodo.

14. World Health Organization. (2019). WHO global report on traditional and complementary medicine.

15. Nitta, N., \& Kawabata, K. (2007). Current state and problems of complementary and alternative medicine in nursing -from the survey on learning and implementing complementary and alternative medicine by nurses who works at hospice and palliative care wards. Journal of the Japanese 
Society for Complementary and Alternative Medicine, 4(1), 23-31.

16. Booth-Laforce, C., Scott, C.S., Heitkemper, M.M., Cornman, B.J., Lan, M.C., Bond, E.F., Swanson, K.M. Complementary and alternative medicine (CAM) attitudes and competencies of nursing students and faculty: results of integrating CAM into the nursing curriculum. J Prof Nurs, 26, 293300.

17. Oyama, A., Nakajima, K., Nakajima, M., Koujitani Y., Okada A., Nishiyama Y. (2013). Research on education of complementary and alternative medicine/therapy in nursing universities. (First Report) -Introduction status of complementary and alternative medicine/therapy at nursing universities nationwide. Journal of the Society for Integrative
Medicine Japan, 6(2), 45-50.

18. Fujisawa, H., Kumasaka T., \& Kudo, K. (2018). Consideration from the student evaluation in the exercises of adult nursing chronic-compare the time allocation of the exercises. Study of Educational Practice Methodology, 4(2), 31-40.

19. Arai, K., Takeuchi, K., Kigure, T., Hayashi, M., Ishimitsu, F., Furuya, T. (2011). Literary research regarding independence in nursing students considering teaching methods to foster independence-. Mejiro University, Health Science Research, 4, 69-75.

20. Jasemi, M., Whitehead, B., Habibzadeh, H., Zabihi, R.E., Rezaie, S.A. (2018). Challenges in the clinical education of the nursing profession in Iran: A qualitative study. Nurse Educ Today, 67, 21-6. 